\title{
A STUDY OF IMMEDIATE POSTPARTUM IUCD INSERTION IN VAGINAL VS CAESAREAN DELIVERIES
}

\author{
Madhu Digra', Ravinder Kumar²
}

${ }^{1}$ Consultant Gynaecologist, Department of OBG, Government Dh Kathua, Jammu and Kashmir, India.

${ }^{2}$ Consultant Surgeon, Department of General Surgery, GMC, Jammu and Kashmir, India.

\section{BACKGROUND}

\section{ABSTRACT}

Immediate postpartum IUCD insertion is an effective, safe and reversible method of family planning, which provides contraception to women before discharge from the delivery settings.

The objective of this study was to evaluate the complications, safety, efficacy and continuation rate of the two routes of insertion (vaginal and caesarean deliveries).

\section{MATERIALS AND METHODS}

This is a descriptive comparative study done at Govt. Dist. Hospital, Kathua, J and K. Cu T Multiload 375 was inserted after obtaining written consent. 75 women from each group, i.e. vaginal and caesarean delivery groups were studied and compared for a period of 6 months.

\section{RESULTS}

$57.33 \%$ of women from vaginal group and $60 \%$ of women from caesarean group had no complaints. Overall, $12 \%$ of women had menstrual disturbances. Expulsion rate was higher in vaginal group $(9.33 \%)$ and rate of missing strings was higher in caesarean group (17.33\%) with removal of $\mathrm{Cu} \mathrm{T}$ in $10.6 \%$ and $17.3 \%$ in vaginal and caesarean group respectively.

\section{CONCLUSION}

Both routes of insertion of $\mathrm{Cu}$ T, i.e. vaginal and caesarean were found to be safe and effective with good continuation rate $(74.66 \%$ in vaginal delivery and $88 \%$ in caesarean delivery).

\section{KEY WORDS}

Postpartum IUCD, Vaginal Delivery, Caesarean Delivery.

HOW TO CITE THIS ARTICLE: Digra M, Kumar R. A study of immediate postpartum IUCD insertion in vaginal vs caesarean deliveries. J. Evolution Med. Dent. Sci. 2018;7(46):4960-4963, DOI: 10.14260/jemds/2018/1104

\section{BACKGROUND}

The fast growing population of India is a major concern today and there is a dire need of effective and safe methods of family planning for both birth control and optimal birth spacing. In India, $65 \%$ of women in 1 st year of postpartum period have an unmet need for family planning. In this period, only $26 \%$ of women are using some or the other method of family planning. ${ }^{1}$ So healthy spacing of pregnancy must be achieved by postpartum family planning methods. Insertion of an IUCD immediately after delivery plays a major role in National Family Planning Programme and it has many benefits over interval insertion. The uterine bleeding due to insertion is disguised by lochia. Fear of pregnancy is relieved during lactational amenorrhoea and the motivation is higher in the immediate postpartum period. ${ }^{2}$ At certain situations where the baby is distressed, PP-IUCD is a safe and reversible alternative to permanent sterilization. This study is conducted with the purpose to compare the complications, safety, efficacy and continuation rate of PP-IUCD in both vaginal and caesarean delivery groups.

'Financial or Other Competing Interest': None.

Submission 14-10-2018, Peer Review 28-10-2018,

Acceptance 30-10-2018, Published 12-11-2018.

Corresponding Author:

Ravinder Kumar,

Consultant Surgeon,

Department of General Surgery,

GMC, Jammu and Kashmir,

Jammu, India.

E-mail: highcourtnaresh@gmail.com

DOI: $10.14260 /$ jemds/2018/1104

\section{(c) $(1) \ominus$}

\section{MATERIALS AND METHODS}

\section{Study Design}

This descriptive comparative study was carried out in the discipline of Obstetrics and Gynaecology at District Hospital, Kathua.

PP-IUCD insertions were started from May 2017 after formal training of the doctors and the staff nurses. PP-IUCD insertion was done with $\mathrm{Cu}$ T 375 after proper counselling in those women who fulfilled the WHO MEC and had no contraindications for PP-IUCD insertions. Pregnant women admitted and delivering at DH Kathua were counselled and after obtaining informed written consent $\mathrm{Cu}$ T 375 was inserted within 10 minutes of the delivery of placenta in both vaginal and caesarean groups. 75 women were selected from each group (vaginal and caesarean delivery group) and were followed up for a period of 6 months.

\section{Inclusion Criteria}

Women delivering vaginally or by caesarean section, having received pre-delivery counselling for PP-IUCD contraception and given written informed consent.

\section{Exclusion Criteria}

Patients with chorioamnionitis, prolonged rupture of membrane for more than $18 \mathrm{hrs}$., unresolved PPH, anaemia, uterine anomalies and belonging to categories MEC category 3 and 4 .

Post insertion counselling was done and these women were advised to come for follow-up at 6 weeks and then at 6 months. At the follow-up visits they complained of heavy periods, irregular bleeding PV, abnormal vaginal discharges 
and expulsion of IUCD. P/S examination was done to check visibility of $\mathrm{Cu} \mathrm{T}$ strings, abnormal vaginal discharge and bleeding $\mathrm{P} / \mathrm{V}$. Descended strings were trimmed at $2 \mathrm{~cm}$ beyond external os. In c/o missing strings, USG was advised to confirm the presence of IUCD. The request for removal was also considered after proper counseling.

\section{Statistical Analysis}

Data was presented as percentages for qualitative variables. P-value was calculated by Chi-square test/Fisher's exact test using Open Epi software. A p-value of $<0.05$ was considered statistically significant.

\section{RESULTS}

The baseline characteristics including socio-demographic and obstetric characteristics of the study population are shown in Table 1.

The study shows that the majority of women accepting PP-IUCD belonged to the age group of $21-25$ years' group (56\%) followed by the 26 - 30 years' group (32\%). The women from rural background readily accepted the method $(78 \%)$ as compared to urban women $(20 \%)$. $88 \%$ of women in study group belonged to Hindu religion and $12 \%$ belonged to Muslim religion. $60 \%$ of women were from the low socioeconomic status and $40 \%$ were from the middle and high socio-economic group showing the need to convince the women from middle and high class through increased public awareness and strong antenatal counseling. Among the study group, $84 \%$ patients had received formal education and $16 \%$ were illiterates. Overall acceptance of the PP-IUCD was more in women with two living children (45.33\%) followed by primiparous women $(30 \%)$ and $24.66 \%$ in women with three or more living children. At the follow-up, complaints were asked and are shown in Table 2.

43 women $(57.33 \%)$ from the vaginal group and 45 women $(60 \%)$ from the caesarean group had no complaints. At the follow-up from among the vaginal group, 7 women $(9.33 \%)$ had heavy periods and 4 women $(5.33 \%)$ had irregular bleeding PV, whereas 4 women $(5.33 \%)$ from the caesarean group had heavy periods and 3 women (4\%) had irregular bleeding PV. These women were advised haemostatic drugs and were counselled, but were difficult to convince for further continuation of PP-IUCD. Four women with heavy periods and five (from both groups) with irregular bleeding PV got their IUCDs removed. There is no significant association between menstrual complaints and route of insertion. Pelvic pain and LBA was observed in 7 women $(9.33 \%)$ from vaginal group and in 8 women $(10.66 \%)$ in caesarean group, which is almost comparable. Pathological discharge was not observed in any of the women. The rate of missing strings was slightly higher in caesarean group seen in 13 women (17.33\%), whereas it was seen in 8 women $(10.66 \%)$ in vaginal group. The spontaneous expulsion was higher in the vaginal group i.e. 7 women $(9.33 \%)$ as compared to caesarean group i.e. 2 women (2.66\%). No women in the study group had a pregnancy with $\mathrm{Cu} \mathrm{T}$ in situ. The women with missing strings were subjected to USG to confirm the $\mathrm{p} / \mathrm{o} \mathrm{Cu} \mathrm{T}$. There were total 21 women (14\%) who required USG.

Among the women with missing $\mathrm{Cu} \mathrm{T}$ strings, $\mathrm{Cu} \mathrm{T}$ was found in situ in 5 women from the vaginal group and 10 women in the caesarean group. Displaced IUCD in lower uterine segment was noted in 2 women from the vaginal group and 3 from the caesarean group. $\mathrm{Cu} \mathrm{T}$ was removed in all women with displaced IUCD. In one woman, IUCD was found absent and was assumed to have been expelled.

Table 4 shows the reasons for removal of IUCD. IUCD removal was done in $16 \%$ of women from vaginal group and 9.33\% women from caesarean group. The difference is not statistically significant.

At the end of 6 months, the continuation of PP-IUCD is $81.33 \%$ (Table 5) and it was observed that the difference in the rate of continuation of IUCD in both the groups was insignificant.

\begin{tabular}{|c|c|c|c|}
\hline Characteristics & \begin{tabular}{|c|} 
Vaginal GP \\
$\mathrm{N}=75$
\end{tabular} & $\begin{array}{c}\text { Caesarean } \\
\mathrm{N}=75\end{array}$ & $\begin{array}{c}\text { Total } \\
N=150\end{array}$ \\
\hline \multicolumn{4}{|l|}{ (i) Age (Years) } \\
\hline$<20$ & $3(4 \%)$ & $2(2.6 \%)$ & $5(3.33 \%)$ \\
\hline $21-25$ & $45(60 \%)$ & $39(52 \%)$ & $84(56 \%)$ \\
\hline $26-30$ & $19(25.33 \%)$ & $29(38.66 \%)$ & $48(32 \%)$ \\
\hline $31-35$ & $7(9.33 \%)$ & $5(6.66 \%)$ & $12(8 \%)$ \\
\hline$>35$ & $1(1.33 \%)$ & 0 & $1(0.66 \%)$ \\
\hline \multicolumn{4}{|l|}{\begin{tabular}{|l|} 
(ii) Residence: \\
\end{tabular}} \\
\hline Urban & $13(17.33 \%)$ & $20(26.66 \%)$ & $33(22 \%)$ \\
\hline Rural & $62(82.66 \%)$ & $55(73.33 \%)$ & $117(78 \%)$ \\
\hline \multicolumn{4}{|l|}{ (iii) Religion } \\
\hline Hindu & $61(81.33 \%)$ & $71(94.66 \%)$ & $132(88 \%)$ \\
\hline Muslim & $14(18.66 \%)$ & $4(5.33 \%)$ & $18(12 \%)$ \\
\hline \multicolumn{4}{|c|}{ (iv) Educational Status } \\
\hline Literate & $59(78.66 \%)$ & 67 (89.33\%) & $126(84 \%)$ \\
\hline Illiterate & $16(21.33 \%)$ & $8(10.66 \%)$ & $24(16 \%)$ \\
\hline \multicolumn{4}{|c|}{ (v) Socio-economic } \\
\hline Low & $53(70.66 \%)$ & $37(49.33 \%)$ & $90(60 \%)$ \\
\hline Middle & $22(29.33 \%)$ & $38(50.66 \%)$ & $60(40 \%)$ \\
\hline High & 0 & 0 & 0 \\
\hline \multicolumn{4}{|c|}{ No. of Living Children } \\
\hline 1 & $15(20 \%)$ & $30(40 \%)$ & $45(30 \%)$ \\
\hline 2 & $28(37.33 \%)$ & $40(53.33 \%)$ & $68(45.33 \%)$ \\
\hline 3 & $27(36 \%)$ & $5(6.66 \%)$ & $32(21.33 \%)$ \\
\hline 4 & $5(6.66 \%)$ & 0 & $5(3.33 \%)$ \\
\hline
\end{tabular}

Table 1. Baseline Characteristics of the Study Population

\begin{tabular}{|c|c|c|c|c|}
\hline Complaints & $\begin{array}{c}\text { Vaginal GP } \\
\mathrm{N}=75\end{array}$ & \begin{tabular}{|c|} 
Caesarean \\
$\mathrm{N}=75$
\end{tabular} & $\begin{array}{c}\text { Total } \\
\mathrm{N}=150\end{array}$ & P-value \\
\hline $\begin{array}{c}\text { Heavy bleeding } \\
\text { P/V }\end{array}$ & $\begin{array}{c}7 \\
(9.33 \%)\end{array}$ & $\begin{array}{c}4 \\
(5.33 \%)\end{array}$ & $\begin{array}{c}11 \\
(7.33 \%)\end{array}$ & 0.34 \\
\hline $\begin{array}{c}\text { Irregular } \\
\text { bleeding P/V }\end{array}$ & $\begin{array}{c}4 \\
(5.33 \%)\end{array}$ & $\begin{array}{c}3 \\
(4 \%)\end{array}$ & $\begin{array}{c}7 \\
(4.66 \%)\end{array}$ & 0.70 \\
\hline $\begin{array}{c}\text { Pelvic pain and } \\
\text { LBA }\end{array}$ & $\begin{array}{c}7 \\
(9.33 \%)\end{array}$ & $\begin{array}{c}8 \\
(10.66 \%)\end{array}$ & $\begin{array}{c}15 \\
(10 \%)\end{array}$ & 0.78 \\
\hline $\begin{array}{c}\text { Abnormal } \\
\text { vaginal } \\
\text { discharge }\end{array}$ & 0 & 0 & 0 & - \\
\hline Missing strings & $\begin{array}{c}8 \\
(10.66 \%)\end{array}$ & $\begin{array}{c}13 \\
(17.33 \%)\end{array}$ & $\begin{array}{c}21 \\
(14 \%)\end{array}$ & 0.24 \\
\hline Expulsion & $\begin{array}{c}7 \\
(9.33 \%)\end{array}$ & $\begin{array}{c}2 \\
(2.66 \%)\end{array}$ & $\begin{array}{c}9 \\
(6 \%)\end{array}$ & 0.08 \\
\hline Pregnancy & 0 & 0 & 0 & - \\
\hline No complaints & $\begin{array}{c}43 \\
(57.33 \%)\end{array}$ & $\begin{array}{c}45 \\
(60 \%)\end{array}$ & $\begin{array}{c}88 \\
(58.66 \%)\end{array}$ & 0.74 \\
\hline
\end{tabular}




\begin{tabular}{|c|c|c|c|c|}
\hline USG Finding & $\begin{array}{c}\text { Vaginal GP } \\
\mathbf{N = 7 5}\end{array}$ & $\begin{array}{c}\text { Caesarean } \\
\mathbf{N = 7 5}\end{array}$ & Total & P value \\
\hline IUCD in situ & $5(6.66 \%)$ & $\begin{array}{c}10 \\
(13.33 \%)\end{array}$ & $15(10 \%)$ & 0.17 \\
\hline Displaced IUCD & $2(2.66 \%)$ & $3(4 \%)$ & $5(3.33 \%)$ & 0.65 \\
\hline IUCD Absent & $1(1.33 \%)$ & 0 & $1(0.66 \%)$ & 0.32 \\
\hline $\begin{array}{c}\text { Total number of } \\
\text { cases requiring } \\
\text { USG }\end{array}$ & $8(10.66 \%)$ & $\begin{array}{c}13 \\
(17.33 \%)\end{array}$ & $21(14 \%)$ & 0.24 \\
\hline \multicolumn{2}{|c|}{ Table 3. USG findings in cases of Missing Strings } \\
\hline
\end{tabular}

\begin{tabular}{|c|c|c|c|c|}
\hline Reasons & \begin{tabular}{|c|} 
Vaginal GP \\
$\mathrm{N}=75$
\end{tabular} & $\begin{array}{c}\text { Caesarean } \\
\text { GP N=75 }\end{array}$ & $\begin{array}{c}\text { Total } \\
\mathrm{N}=150\end{array}$ & $\begin{array}{c}P \\
\text { value }\end{array}$ \\
\hline $\begin{array}{c}\text { Heavy bleeding } \\
\mathrm{P} / \mathrm{V}\end{array}$ & $4(5.33 \%)$ & 0 & $4(2.66 \%)$ & 0.12 \\
\hline $\begin{array}{c}\text { Irregular } \\
\text { bleeding } \mathrm{P} / \mathrm{V}\end{array}$ & $2(2.66 \%)$ & $3(4 \%)$ & $5(3.33 \%)$ & 0.65 \\
\hline Discharge & 0 & 0 & 0 & - \\
\hline $\begin{array}{l}\text { Pelvic pain and } \\
\text { lower backache }\end{array}$ & $1(1.33 \%)$ & 0 & $1(0.66 \%)$ & 0.38 \\
\hline Displaced IUCD & $2(2.66 \%)$ & $3(4 \%)$ & $5(3.33 \%)$ & 0.65 \\
\hline $\begin{array}{l}\text { Psychological } \\
\text { reasons }\end{array}$ & $3(4 \%)$ & $1(1.33 \%)$ & $4(2.66 \%)$ & 0.31 \\
\hline Total & $\begin{array}{c}12 \\
(16 \%)\end{array}$ & $\begin{array}{c}7 \\
(9.33 \%)\end{array}$ & $\begin{array}{c}19 \\
(12.66 \%)\end{array}$ & 0.22 \\
\hline \multicolumn{5}{|c|}{ Table 4. Reasons for Removal of IUCD } \\
\hline
\end{tabular}

\begin{tabular}{|c|c|c|c|c|}
\hline $\begin{array}{c}\text { Total } \\
\text { Insertion } \\
\text { Followed }\end{array}$ & $\begin{array}{c}\text { Vaginal GP } \\
\mathbf{N = 7 5}\end{array}$ & $\begin{array}{c}\text { Caesarean } \\
\text { GP N=75 }\end{array}$ & $\begin{array}{c}\text { Total } \\
\mathbf{N = 1 5 0}\end{array}$ & P value \\
\hline Expulsions & $7(9.33 \%)$ & $2(2.66 \%)$ & $9(6 \%)$ & 0.08 \\
\hline Removal & $\begin{array}{c}12 \\
(16 \%)\end{array}$ & $7(9.33 \%)$ & $\begin{array}{c}19 \\
(12.66 \%)\end{array}$ & 0.22 \\
\hline Continuation & $\begin{array}{c}56 \\
(74.66 \%)\end{array}$ & $\begin{array}{c}66 \\
(88 \%)\end{array}$ & $\begin{array}{c}122 \\
(81.33 \%)\end{array}$ & $\begin{array}{c}0.04 \\
\text { (significant) }\end{array}$ \\
\hline \multicolumn{5}{|c|}{ Table 5. Continuation Rate of PP-IUCD at 6 months of } \\
Follow-Up
\end{tabular}

\section{DISCUSSION}

The postpartum period is a unique phase in the life of a woman and her baby. It is a time of transition, adjustment and adaptation along with significant biological, social and psychological changes. Family planning programmes recognised the importance of providing family planning to $\mathrm{PP}$ women, because it is during the extended PP period when a woman's fertility returns and where unmet need for family planning is high. Moreover, return of fertility is unpredictable and ovulation may occur prior to return of menses. ${ }^{3}$ So PPIUCD seems to be safe, long-lasting, easily accessible, highly effective and reversible contraceptive method of postpartum lactating women. 4 Majority of women accepting PP-IUCD were from the age group of 21 - 25 yrs. in both the vaginal and caesarean group followed by $26-30$ yrs. This may be because the fertility is higher in this age and majority of women admitted with full-term pregnancy were from the same age group. Studies by Usha Ram et al, Halder et al and Kanwat B et al also observed the same findings. ${ }^{4,5,6}$ The acceptance was more in rural women $(82.6 \%$ and $73.3 \%$ in vaginal group and caesarean group respectively) as compared to urban women $(17.3 \%$ and $26.6 \%$ respectively). Also the women from low socio-economic status showed more acceptance to PP-IUCD (60\%) as compared to middle and high socio-economic group, probably because they belonged to remote areas with infrequent postpartum care and poor accessibility to health facilities. They utilised this opportunity wisely after proper counseling. Urban women showed inclination towards interval IUCD insertion and other methods of contraception. Women with 2 living children had more acceptance for PP-IUCD as a limiting method of contraception, which is reversible also. Somi $\mathrm{M}$ et al also reported the similar incidence of P2 in both groups $(26.7 \%)$ in vaginal and $68.7 \%$ in caesarean groups. ${ }^{7}$ At the follow-up visits, the heavy menstrual periods and irregular bleeding PV was reported by $9.33 \%$ and $5.33 \%$ women in the vaginal group and $5.33 \%$ and $4 \%$ respectively in the caesarean group. Pelvic pain was $7 \%$ and $8 \%$ in both groups respectively. This shows that irregular bleeding PV and pelvic pain and LBA was not influenced by the route of insertion. Different studies report different rate of bleeding PV after PPIUCD insertions varying from $23.5 \%$ as reported by Mishra S et al to as low as $5.5 \%$ by Kumar $S$ et al, Table $3.8,9$ Halder et al found $30 \%$ of missing tails in caesarean group and $17.7 \%$ in vaginal group, whereas Hooda $\mathrm{R}$ et al found a rate of missing tails of $55.1 \%$ in caesarean group and $22.1 \%$ in vaginal group. ${ }^{10}$ In the present study, the incident of missing strings is found in $10.66 \%$ in vaginal group and $17.33 \%$ in caesarean group. Expulsion of $\mathrm{Cu} \mathrm{T}$ is $9.33 \%$ in vaginal group as compared to $2.6 \%$ in caesarean group. Low expulsion in caesarean group may be because of the better fundal placement of $\mathrm{Cu} \mathrm{T}$ under visualisation. Gupta et al also reported low expulsion after caesarean expulsion than vaginal delivery. In the present study the continuation rate of PP-IUSD is $74.66 \%$ for vaginal group and $88 \%$ for caesarean group, which is quite good. This may be because of the continued motivation of women, selection as per recommended MEC and growing public awareness, Table 5. Halder et al found continuation rate of $88 \%$ in vaginal GP and $94 \%$ in caesarean GP and Mishra et al found $91.1 \%$ of continuation rate in their study. 5,8

\section{CONCLUSION}

From the study results, it can be concluded that insertion of an IUCD in the immediate PP period is safe, convenient, very effective, reversible and a long-term contraceptive method which provides contraceptive effect soon after the birth. Both the routes of insertion vaginal and caesarean are equally safe and effective, though the expulsion rates are slightly higher in vaginal group and rate of missing strings is little more in caesarean group, but still the continuation rate is quite high in caesarean group.

\section{ABBREVIATIONS}

1. PP: Postpartum.

2. IUCD: Intrauterine Contraceptive Device.

3. PP-IUCD: Postpartum Intrauterine Contraceptive Device.

4. Cu T: Copper T.

5. USG: Ultrasonography.

\section{REFERENCES}

[1] Post-partum IUCD reference manual, Family Planning Division. Ministry of Health and Family Welfare, Government of India, 2010: p. 1-3.

[2] Grimes D, Lopez LM, Schulz KF, et al. Immediate Postpartum insertion of intrauterine devices. Cochrane Database Syst Rev 2010;12(5):CD003036. 


\section{Jemds.com}

[3] Counselling for post-partrum family planning and post-partum IUCD - Reference Manual (PDFP): Training.www.Ky health Org.

[4] Kanwat B, Salodia L, Chauhan M, et al. Comparative study of post-partum intrauterine contraceptive device in vaginal and intra caesarean insertion. Int J Reprod Contracept Obstet Gynecol 2017;6(11):493844.

[5] Halder A, Sowmya MS, Gayen A, et al. A prospective study to evaluate vaginal insertion and intra-caesrean insertion of post-partum intrauterine contraceptive device. J Obstet \& Gynecol India 2016;66(1):35-41.

[6] Usha R. Ph.D, Associate Professor, Dept. of Public Health and Mortality Studies, International Institute for population Sciences, MUMBAI - paper presentation in the International Conference on Family Planning, at Munyonyo, Uganda. November 15-18, 2009.

\section{Original Research Article}

[7] Soni M, Sharma V, Bhat MP, et al. Post-placental postpartum intrauterine contraceptive devices insertion: our scenario. Int J Reprod Contracept Obstet \& Gynecol 2016;5(3):766-9.

[8] Mishra S. Evaluation of safety, efficacy and expulsion of post-placental and intra-casarean insertion of intrauterine contraceptive devices (PPIUCD). J Obstet Gynecol India 2014;64(5):337-43.

[9] Kumar S, Sethi R, Balasubramaniam S, et al. Women's experience with postpartum intrauterine contraceptive devices use in India. Reprod Health 2014;11:32.

[10] Hooda R, Mann S, Nanda S, et al. Immediate postpartum intrauterine contraceptive device insertions in caesarean and vaginal deliveries: a comparative study of follow-up outcomes. Article ID 7695847, Int J Reproduce Med 2016;2016: p. 5. 